\title{
In prototypical autism, the genetic ability to learn language is triggered by structured information, not only by exposure to oral language.
}

\author{
Laurent Mottron ${ }^{1, *}$, Alexia Ostrolenk ${ }^{2}$, and David Gagnon ${ }^{3}$
}

\begin{abstract}
${ }^{1}$ University of Montreal, Psychiatry and Addictology Department, 2900 blvd Edouard-Montpetit, Montreal, QC Canada H3T 1J4; CIUSSS-NIM, Riviere-des-Prairies Hospital, 7070 blvd Perras, Montreal, QC Canada H1E 1A4; laurent.mottron@gmail.com

${ }^{2}$ University of Montreal, Psychiatry and Addictology Department, 2900 blvd Edouard-Montpetit, Montreal, QC Canada H3T 1J4; CIUSSS-NIM, Riviere-des-Prairies Hospital, 7070 blvd Perras, Montreal, QC Canada H1E 1A4; alexiaostrolenk@gmail.com

${ }^{3}$ University of Montreal, Psychiatry and Addictology Department, 2900 blvd Edouard-Montpetit, Montreal, QC Canada H3T 1J4; CIUSSS-NIM, Riviere-des-Prairies Hospital, 7070 blvd Perras, Montreal, QC Canada H1E 1A4; gagnon_david@hotmail.com

* Correspondence: Correspondence: Laurent.mottron.cnmtl@ssss.gouv.qc.ca; Tel: 1-514-972-4841
\end{abstract}

\begin{abstract}
What does the way autistics bypass, learn, and eventually master language tell us about humans' genetically encoded linguistic ability? In this theoretical review, we argue that autistic nonsocial acquisition of language, as well as autistic savant abilities, provide a strong argument for an innate, human-specific orientation toward (and mastery of) complex embedded structures. Autistic non-social language learning may represent a widening of the material processed during development beyond oral language. Structure detection and manipulation and generative production of non-linguistic embedded and chained material (savant abilities in calendar calculation, musical composition and interpretation, three-dimensional drawing) may thus represent an application of such innate mechanisms to non-standard materials. Typical language learning through exposure to the child's mother tongue may represent but one of many possible achievements of the same capacity. The deviation from typical language development in autism may ultimately allow access to oral language, sometimes in its most elaborate forms, but also explains the possibility of the absence of its development when applied exclusively to non-linguistic structured material. Such an extension of human capacities beyond, or in parallel to, their usual limits call into question what we consider to be specific or expected in humans and, therefore, does not necessarily represent a genetic "error". Regardless of the adaptive success or failure of non-social language learning, it is up to science and ethical principles to strive to maintain autism as a human potentiality to further foster our vision of a plural society.
\end{abstract}

Keywords: language, autism, development, perception, veridical mapping, autistic interests, deep phenotypes, clusters/subtypes, neurodevelopment

Autism is a neurodevelopmental variant currently defined by the association of reduced or atypical overt socio-communicative behaviors, intense interests, repetitive movements, and perceptual manifestations [1]. Its prevalence is highly dependent on the heterogeneity tolerated by its definition, from approximately $1 / 200$ for prototypical autism to $1 / 50$ for the autism spectrum as currently defined [2]. In its prototypical form, autism involves a major delay in the processing and production of oral language and, on the contrary, the preservation of non-verbal intelligence [3,4]. In about half of autistic individuals (depending on the stringency of the prototypical phenotype), it is associated with a series of talents and strengths, amongst which the most documented are pattern detection and manipulation [5]. 
We are at a critical point in advancing our knowledge about the role of genetics in the occurrence of autism. On the one hand, having an autistic condition is highly concordant in monozygotic twins and clinical pictures variably related to this condition show familial aggregation in siblings [6]. This tells us beyond any doubt that genetics are involved in the etiology of autism. On the other hand, the role of rare variants with a strong effect, essentially de novo, explains less than $5 \%$ of the overall heritability of autism [7]. It mainly concerns the subgroup of "syndromic" autistics, who are often non-verbal and have an intellectual disability, which is poorly representative of the majority of the autism "spectrum" as currently defined (see [8,9] for the justification of studying distinctly syndromic and non-syndromic autism). Another limitation in our understanding of the contribution of genetics to autism is the variability of the transmitted phenotype. For example, symptom severity can be highly variable between autistic monozygotic twins. [6]. The specific form taken by the condition is not transmitted through the same mechanisms as having the condition. This is particularly true for oral language, which can range from almost non-existent, in non-verbal or minimally verbal autistic people, to the highest levels of sophistication, as in individuals designated until recently as those with "Asperger's syndrome".

The human capacity to detect and then master the language to which they are exposed in their environment is the very example of gene-environment co-evolution [10]. It allows for variability in the nature of the language learned - there are seven thousand languages on Earth with numerous phonetic and morphosyntactic variations, and even distinct forms of externalization, such as sign language. Despite the vast repertoire of languages, the developmental sequence of acquisition for all languages is similar in neurotypical children. This innate ability that characterizes the human species, that of learning and then producing oral language after being exposed to it, is atypical in autism. We are therefore at the crossroads between a condition, autism, and a faculty, language acquisition, that are both genetically determined. Each of the two influences the scientific perspective on the other, leading us to consider what autism can teach us about the innate nature of language, its mode of acquisition, and use.

In this conceptual article, we will tackle the following question: what, in our conception of the innate human ability to acquire language through participation in social interaction and exposure to oral language, needs to be adapted to enable the non-social acquisition of language that characterizes prototypical autism? We will limit our study to nonsyndromic phenotypes. We will therefore not discuss the molecular mechanisms involved in the ability to speak and read, nor the effect of de novo mutations of "language genes" on language acquisition in autism, such as, for example, the most studied of them, Fox P2, which is not involved in autism [11]. Neither will we address the specific effect of the common variants with a weak effect, listed by GWAS, which has inventoried hundreds of rarely replicated genes that are minimally informative on their combined activity [12], and stumbling on the problem of heterogeneity [13].

\section{The nature and level of differences in language ability among humankind.}

The alteration of two central and interrelated human abilities in autism, socialization and language, raises questions about the variability tolerated by the human species [14] (p. 178). We endorse the idea that the constructionist model, that stipulates a prerequisite of reciprocal social interaction for autistic language learning, has limitations to account for the figures of language acquisition in prototypical autistic people [15]. We further propose a new perspective on how autism could enlighten our understanding of the ability of innate language acquisition: autism and typical development can provide information about each other [16].

As an alternative to considering autism as a genetic "error", we may consider this human variant as displaying another form of species-specific intelligence, extending, for better or worse, the realization of initial human possibilities. Atypical learning and processing of complex information in autism provides information on the level of abstraction, 
complexity, or versatility of what makes us human in terms of information processing. It is the structural properties and the level of complexity, broadly defined, and their successful manipulation by humans that is species-specific. The normocentric constructs forged to account for the material-specific language acquisition of non-autistic children when they are exposed to oral speech (e.g., language acquisition device) may not apply to the same extent to autistic people. Particularly, their "material specificity to oral language" has to be modified [17]. Alternatively, the alteration of a function (e.g., language learning) in autistics is not straightforwardly equated with its deficit. This article aims to unify the learning of language by autistic people and its chronology, communicational peculiarities, relationship with other cognitive systems, and extremes of performance or challenges. We will discuss how a genetically determined human function, language learning, may lead to typical (e.g., mastery of language), as well as atypical, achievements (e.g., special abilities). Despite its non-conformity to the dominant learning pathways, it may still represent the achievement of the same human function.

\section{Autistic learning of complex structures: the veridical mapping model as a structure acquisition device.}

\subsection{From the superior role of perception in autism to the mastery of generative structures.}

Relative (in comparison to their performance in other domains) and, in some cases, absolute (in comparison to the general population) strengths in autistic people have been reported over the last two decades. More than half of autistic individuals present at least one of these strengths $(46 \%$ had at least one parent-reported talent and $23 \%$ at least one personal strength [18]; $62.5 \%$ had isolated skills and $58 \%$ had perceptual peaks [19]). The frequency of autistic strengths largely surpasses the more visible phenomenon of autistic "savants". These strengths involve low-level perceptual over-functioning, such as pitch discrimination [20], absolute pitch, and pitch memory [21], visual discrimination (here they outperform typical individuals by $30 \%$ at the group level [22]), pattern detection and manipulation (particularly of letters, even in the absence of oral language [23], for which they detect as much as twice the number of targets that typical children do in certain tasks), musical memory [24], and mental rotation [25], up to and including fluid intelligence in non-verbal abstract reasoning [26].

The ENHANCED PERCEPTUAL FUNCTIONING model (EPF; [27]) proposes that perception in autism demonstrates higher performance, greater involvement, and more autonomy than that observed in the general population. This model is used as an explanatory framework for multiple behavioral, cognitive, and brain imaging variants related to perception and their interaction with the other cognitive functions that characterize autism. Two complementary models have been developed. The VERIDICAL MAPPING model (VM; [28]) covers the structural homologies shared by informational material involved in autistic savant abilities, either simple (e.g., absolute pitch) or complex (e.g., calendar calculation). It proposes a mechanism for the developmental and creative extension of autistic special abilities that involve language-like structures, such as calendar calculation, and those which are essentially nonverbal, such as three-dimensional drawing. This will be discussed in the following section of this paper. Finally, the TRIGGER-THRESHOLD-TARGET model (TTT; [29]) covers the neurobiological mechanisms of microcellular plasticity responsible for EPF, which will not be addressed here.

\subsection{Veridical mapping and autistic "special abilities".}

The first principle of the veridical mapping model states that autistic preschoolers spontaneously detect and orient themselves preferentially towards complex structures that exhibit a higher density of isomorphisms -any perceptual structure with a certain structural similarity- than those for which these properties are absent or less rich. According to this hypothesis, it is the multi-scale, recursive nature of information to which they are exposed that makes it of interest and triggers the implicit learning of their rules and regularities. This information (pitch scales, colours, numbers, and letters) is presented to 
the child in highly redundant chains, therefore exhibiting embedded isomorphisms. Written symbols and pitches are also a family of forms that share a configurational resemblance and a high level of within- and between-code recurrences. They form larger redundant units at a higher level of organisation, such as words or musical sentences, that share a roughly similar organisation/syntactic structure.

A second principle of the VM model is indeed that the autistic brain tends to map isomorphic structures presented in different perceptual modalities onto each other. In the same way that an information format maximizing redundancy triggers an interest and implicit learning, the structural similarity between two layers of perceptual information, or "between-code isomorphisms", triggers stable, intermodal connectivity between two perceptual expertise regions, possibly favoured by enhanced microstructural plasticity [24]. Absolute pitch, synesthesia, and early knowledge of letters and numbers, indeed, involve the stabilisation of coupling between homologous elements belonging to ordered series of auditory and visual information (the name of a note with the note, the name of a letter with a color or another sensation, the name of a letter with a grapheme) [30]. Several manifestations of language-perception coupling displaying a VM structure are indeed observed more frequently in autism: absolute pitch (11\% of autistic people [31]), synesthesia (up to $20 \%[32,33]$ ) and hyperlexia $(6 \%[34,35]$ to $24 \%$ of autistic people, according to the definition and population studied) [5]. The information involved is generally composed of small, perceptually segmented units that present a familial resemblance. The special ability, in this case, consists of producing an element when presented with another coupled item, such as a note and its name for absolute pitch, a letter and a particular color or sensation for synesthesia, and pronounced words and written code for hyperlexia.

The two VM principles may act concurrently, as the choice of ordered series implies an initial grasp of a structure common to elements with a familial resemblance, before their mapping with another homologous element of another hierarchical/ordered sequence [30]. The neuronal stabilization of such intermodal couplings, linking together the homologous elements of two isomorphic structures, forms the unit on which future autistic "special abilities", mastering complex syntax and producing complex chains according to the rules of this syntax, are built: certain autistic musicians have perfect pitch, certain calendar calculators presented with initial hyperlexia, and synesthesia is common to both.

\subsection{Savant syndrome as an extreme of autistic abilities}

Certain children, of whom a disputed but large majority are autistic, develop extreme self-taught abilities involving complex sets of "syntactic" rules, such as mastering language heard only through television and/or cracking the codes of calendrical regularities, and other examples [36,37]. This has been characterized as "savant syndrome". Savants generate the flexible use of the units of a sometimes idiosyncratic domain composed of embedded structures (See table 1), ultimately manifesting creative mastery of the laws that compose them, which is not limited to memorization. A striking example is calendar calculation, in which a person who has shown early detection of numbers and letters spontaneously turns to calendars (e.g., [38]). From exposure to only a limited number of calendars, they implicitly understand the laws that govern them. They can then determine the day of the week corresponding to a given date without using an explicit algorithm. Access to this information is bidirectional: the person can give a list of the years in which March begins on a Friday as quickly as they can give the day of the week of July 31, 1914. As discussed in the following, the structural similarity between autistic special abilities and the way autistic people master language may be reciprocally informative. 
Table 1. Common unfolding of non-autistic acquisition of oral language and autistic savant abilities.

\begin{tabular}{|c|c|c|c|c|c|c|c|c|}
\hline Competence & $\begin{array}{l}\text { Unity of } \\
\text { information }\end{array}$ & Recursivity & $\begin{array}{l}\text { Embedded } \\
\text { structure }\end{array}$ & $\begin{array}{l}\text { Triggering } \\
\text { exposure }\end{array}$ & $\begin{array}{l}\text { Veridical } \\
\text { Mapping }\end{array}$ & Generativity & Associated behaviors & Imprinting effect \\
\hline Non-autistic speech & Syllables & $\begin{array}{l}\text { Embedded } \\
\text { sentences }\end{array}$ & Syntax & $\begin{array}{l}\text { Oral mother } \\
\text { tongue }\end{array}$ & $\begin{array}{l}\text { language-world } \\
\text { referential } \\
\text { mapping }\end{array}$ & $\begin{array}{l}\text { Producing new } \\
\text { well-formed } \\
\text { sentences }\end{array}$ & $\begin{array}{l}\text { Imitation, } \\
\text { joint attention } \\
\& \text { reference }\end{array}$ & $\begin{array}{l}\text { Irreversibility of } \\
\text { Mother tongue }\end{array}$ \\
\hline $\begin{array}{l}\text { Autistic } \\
\text { hyperlexia }\end{array}$ & $\begin{array}{l}\text { Letters and } \\
\text { numbers }\end{array}$ & $\begin{array}{l}\text { Letters embedded in } \\
\text { words and sentence } \\
\text { chains }\end{array}$ & Written code & $\begin{array}{l}\text { Combined } \\
\text { written and } \\
\text { oral signs }\end{array}$ & $\begin{array}{l}\text { Isomorphic } \\
\text { graphic-phonic } \\
\text { structures }\end{array}$ & $\begin{array}{l}\text { Reading } \\
\text { unknown } \\
\text { words }\end{array}$ & $\begin{array}{l}\text { Orientation } \\
\text { toward written } \\
\text { code }\end{array}$ & $\begin{array}{l}\text { Restricted/intense } \\
\text { interest for printed } \\
\text { material }\end{array}$ \\
\hline $\begin{array}{l}\text { Verbal savant ability } \\
\text { (e.g. calendrical } \\
\text { calculation) }\end{array}$ & $\begin{array}{l}\text { Dates and } \\
\text { calendar } \\
\text { lexicon }\end{array}$ & $\begin{array}{l}\text { Letters \& numbers } \\
\text { embedded in } \\
\text { month-day-year } \\
\text { calendars }\end{array}$ & $\begin{array}{l}\text { Calendrical } \\
\text { structures }\end{array}$ & Calendars & $\begin{array}{l}\text { Isomorphic } \\
\text { calendar } \\
\text { structures }\end{array}$ & $\begin{array}{l}\text { Producing } \\
\text { non-memorized } \\
\text { dates }\end{array}$ & $\begin{array}{l}\text { Intense interest } \\
\text { for dates }\end{array}$ & $\begin{array}{l}\text { Restricted/intense } \\
\text { interest for } \\
\text { calendars }\end{array}$ \\
\hline $\begin{array}{l}\text { Visuo-spatial savant } \\
\text { ability } \\
\text { (e.g. 3D drawing) }\end{array}$ & Geons & $\begin{array}{l}\text { Micro 3D scale } \\
\text { embedded in 3D } \\
\text { macro scale }\end{array}$ & $\begin{array}{c}\text { Mechanical } \\
\text { structures }\end{array}$ & 3-D objects & $\begin{array}{l}\text { Isomorphic } \\
\text { visual-graphic } \\
\text { structures }\end{array}$ & $\begin{array}{l}\text { Producing } \\
\text { graphic } \\
\text { 3D } \\
\text { transformations }\end{array}$ & $\begin{array}{l}\text { Lining up, } \\
\text { prolonged visual } \\
\text { inspections }\end{array}$ & $\begin{array}{l}\text { Restricted/intense } \\
\text { interest for 3-D } \\
\text { patterns }\end{array}$ \\
\hline $\begin{array}{l}\text { Musical savant ability } \\
\text { (e.g. memorizing, } \\
\text { interpreting, and } \\
\text { composing musical } \\
\text { pieces }\end{array}$ & Pitches & $\begin{array}{l}\text { Pitches embedded in } \\
\text { musical sentences and } \\
\text { pieces }\end{array}$ & $\begin{array}{l}\text { Musical } \\
\text { structures }\end{array}$ & $\begin{array}{l}\text { Musical } \\
\text { pieces }\end{array}$ & $\begin{array}{l}\text { Isomorphic } \\
\text { musical patterns }\end{array}$ & $\begin{array}{l}\text { Composing new } \\
\text { musical } \\
\text { sentences }\end{array}$ & $\begin{array}{l}\text { Auditory searches } \\
\text { and avoidance }\end{array}$ & $\begin{array}{l}\text { Restricted/intense } \\
\text { interest for music }\end{array}$ \\
\hline
\end{tabular}




\section{The Developmental sequence of language acquisition in autism.}

\subsection{The apparent heterogeneity of the language phenotype in autism.}

Language in autism is atypical in many ways - the path and mode of learning, semantics, intonation, thematic content, and pragmatics. These were considered to be diagnostic criteria in the early years of the description of autism in school-age children [39]. Moreover, the reduced intention to communicate, and most often the very ability to communicate, is intrinsic to the current definition of autism [1].

However, do these atypical characteristics lessen the autistic individual's aptitude to master the formal aspects of language? Several observations in the half-century following the discovery of this condition led to the dissociation of language skills from socio-communicative atypicalities. The same people who presented marked and prototypical clinical profiles at preschool age and who were minimally verbal could sometimes later correctly use language in adulthood. Therefore, that which was deficient or atypical in these autistics' use of language did not necessarily concern language competence itself. This finding is consistent with the integration of individuals first described by Asperger into the definition of autism. These individuals master complex language from childhood, whereas as adults they exhibit socialization skills and types of interests similar to those described by Kanner.

How, then, can the same condition be associated with such wide variations in the acquisition, timing, form, and use of language, from silence to exceptional mastery? The operative conclusion to this question in the current diagnostic criteria of autism is that the level of language does not contribute to the identification of autism. Its impairment or its integrity would only modify the presentation and adaptive capacity of autistic people. Alternatively, assimilating language figures in autism to a dimensional, uninformative, quasi-random variation [40] may miss precious heuristic information on the mechanisms at play in this condition for language, as well as any type of autistic learning mechanism and its unfolding. Language development in autism, in its various forms, represents an example of the "Wilson effect" [41], that of genetic constraints being more informative for the final development of a function than to its initial presentations.

Consistent with this position, there are three orthogonal variables that structure the autistic language phenotype: the age of speech onset, the presence or absence of an intellectual disability, and comorbidity with developmental language disorder (DLD). First, the age of speech onset of people diagnosed with autism displays a bimodal distribution. One subgroup presents with a speech onset delay (SOD) or the early regression/loss of language (or marked, transient atypicalities without a delay in a small proportion of them). It corresponds to individuals who are diagnosed early and to the first prototypical description of autism. Another subgroup does not present with SOD. It broadly maps with the former category of Asperger syndrome, now considered in DSM 5 as autism with typical intelligence and language structure. It generally consists of individuals diagnosed around the end of their preschool years or later. These individuals represent approximately $20 \%$ of the overall prevalence of the autism spectrum [42], but their prevalence is increasing based on current drift of the criteria. A third subgroup contains autistic people with a nonverbal intellectual disability, frequently accompanied by identified neurogenetic syndromes, which combine the language limitation associated with intellectual deficiency to an autistic language acquisition trajectory (approximately $10-15 \%$ of the overall prevalence [7]). Finally, certain autistic children display the same type of language deficits that are found in isolation in non-autistic children with DLD [43]. This subgrouping may oversimplify clinical reality, as certain individuals simultaneously display limitations of several of these functions/groups. Here, we will focus on the first group, which may limit the generalisation of our model to other subgroups. Prototypical autism combines historical primacy and fast and reliable identification with the most clearly individualised language phenotype $[8,9]$.

3.2. Pre-clinical phase: Attentional differences preceding recognition of the syndrome. 
Autism in its prototypical form is usually detected by parents around the middle of the second year of life through a set of mainly socio-communicative signs (decreased response to name, social synchrony, oriented smiling, initiative and response to joint attention, imitation, and eye contact) and language signs (absence of language development or loss of the few words already acquired by the child) [44,45].

Before autism is visible to a non-expert observer, low- and high-risk groups are differentiated by the nature of their attention towards social and non-social targets. This has been highlighted by prospective longitudinal studies of siblings of children already diagnosed with autism, one fifth of whom will be diagnosed later. Perceptual signs start to diverge from typical development at nine months of age, on average [46], whereas social signs start to diverge at 12 months [47]. From the age of 13 months, alterations in these two domains predict, additively but independently and sometimes in isolation, the subsequent occurrence of a prototypical autistic presentation [48]. Both precede the objectivation of language delay [49].

A meta-analysis of the non-social signs preceding the diagnosis [50] revealed that children "at risk" for autism (siblings of an autistic child) visually fix on objects for longer durations [51,52] at the end of the first year of life, regardless of their future diagnosis. At 12 months, most children who will later be diagnosed with autism present atypical visual exploration [53]. Prolonged target fixation can be seen either as a deficit of disengagement [54] or, on the contrary, as the effect of special capabilities in the detection of targets and visual search, particularly of letters, as attested by several convergent studies [23,55-57]. The latter is consistent with one third to one half of diagnosed autistic children exhibiting enhanced nonverbal abilities for their chronological age [58]. The manifestations of auditory hypersensitivity (covering their ears with their hands when exposed to physical noises or a human voice) are maximal during the nonverbal or minimally verbal period [59]. Atypical socio-communicative behaviors and interests are observed before the emergence of formal language, even before its atypical development is noticed.

\subsection{Atypical language progression.}

In the preschool years, the attention of autistic children is directed towards interests that are mostly non-social. This is coherent with the observed plateau of several years without evident progress in the development of social, language, adaptive, and imaginative neurotypical skills [60-62]. This is emphasized in the case of oral language when the apparent plateau follows a regression - the loss of previously acquired words after apparent typical development. In these children, the first words are reported by parents to occur earlier than those of typical children, but the time period separating the utterance of the first words and two-word sentences is at least double [63]. These autistic children may remain silent for several years or only utter unrecognizable vocalizations, idiosyncratic to each child.

The language plateau is not always characterized by complete silence: the absence of communicative language (requests or instances of interactive speech, the use of pragmatic terms) can coexist with "labels" identifying "natural kinds" [64]. The child can thus name aloud the shapes he/she encounters, most often those belonging to an ordered series that he/she is interested in (letters, numbers, colors, geometric shapes, animals). When these shapes are letters, the situation has been individualized as hyperlexia. In its most extreme forms, the child reads fluently but does not speak (see for example: [65-68]); such a large discrepancy between reading skills and oral language level was found in 29 of the 82 published cases of hyperlexia [69]. Access to and the understanding of language codes in such cases relies more on non-communicative forms of language than in neurotypical children. This is consistent with the results of a preliminary study suggesting that half of prototypical autistic children with access to screens present an interest in and knowledge of letters and numbers during their third year of life, significantly ahead of general population norms (U.S. Department of Education) [70]. For some, letters are learned in a language other than that spoken at home (personal observation, LM \& AO; see also [69,71,72]. 
The progression of expressive language is marked by a succession of atypical language features, modulated by chronological age and IQ: immediate echolalia in the presence of a frequently age-appropriate phonology [73], then delayed echolalia, then pronoun reversal, then stereotyped language [74]. Immediate echolalia is more characteristic of autism when it consists in the verbatim repetition of exchanges between people that are not addressed to the child, now mostly extracted from television/YouTube programs (personal observation, LM). It differs from the echolalia of sentences addressed to the child observed during typical language acquisition and predominant in non-autistic language disorders. Immediate echolalia testifies to phonological (prosodically contrastive) echolalia [75], which demonstrate its partially communicative and semantic nature or intention.

Delayed echolalia involves sentences that are presented several times in the same way in the environment at some distance from their occurrence: cartoons, advertisements, or parental instructions. We can sometimes grasp, on the fly, the transformation of stereotyped language into syntactically normal language in the form of mitigated echolalia [76], the lessening of deferred echolalia by substitution of one of the original terms by a more adequate term for the current utterance situation. Better understanding is associated with increased mitigation [77]. Stereotypical language is functional, but keeps traces of its origin (word order, adult language, accents), and is heard identically on multiple occasions. In an extension of this phenomenon, in pronoun reversal (when the child asks for a drink by saying ' you want water'), the child makes a request maintaining the personal pronoun used by others to address him/her. Such pronominal reversal represents the last form of delayed echolalia before the mastery of "normal" language. However, it retains a certain level of rigidity, hyper-grammaticality, and formalism [78-80], which retain their diagnostic value in adulthood.

All of these peculiarities are most prevalent around the age of 4 to 6 years, at the resumption of language at the end of the plateau, and mostly disappear when language normalizes [81]. The plateau can last until the age of 8 [82], 9 [83], or 11 [84]. The late emergence of language is also well documented in autism, as shown by Picket et al. [85], who identified 167 autistic children who acquired language after five years of age in a conservative review. Anecdotal cases of language recovery in adulthood have also been reported [86]. The slope of acquisition, once language progression has restarted, is generally steep [83,87]. Kanner [88] noticed that nonverbal autistic children surprised their parents in emergency situations when they uttered grammatically correct sentences, suggesting that they had accumulated a large amount of language information before their first use of speech. Two studies $[89,90]$ reported the sudden emergence of fully formed speech after the apparition of reading skills in several subjects. The extent of oral language recovery has been associated with the level of nonverbal IQ [63,83,87].

Meta-analyses on the effect of interventions on language recovery, whether it is before five years of age or later, show that they have only a minimal influence on the language development of these children [91-93]. Approximately 7\% of autistic children naturally show a quick catching up of their language skills, going from a generally delayed language ability to the expected language level for their age [83,87]. Language, when it appears, is essentially self-taught [15] and autonomous access to written or web-based information could play a major role in its emergence $[69,71,72]$. Although nonverbal IQ remains the main predictor of ultimate language access, it does not guarantee it [94]. A quarter [95,96] to a half [97] of autistic children under the age of 10 are considered to be mute or minimally verbal. The notion of nonverbal autism must indeed be viewed critically, as its definition is uncertain [98].

In summary, the maturation of oral language in prototypical autistic children follows a "bayonet-shaped" sequence, composed of three steps: a) an almost normal start but with an atypical imbalance of interests and attention for auditory and verbal stimuli; b) a nonverbal or minimally verbal plateau, with or without the loss of the first words; and c) atypical, rapid resumption, resulting most often in syntactically correct language after six years of age [63]. In a substantial proportion of cases, this sequence is coupled with an 
early interest in written code, with decoding skills superior to comprehension in the hyperlexic period. In most cases, it predicts catching up in reading comprehension after five years of age [99]. The nature of the oral utterances or reading prerequisites that the child demonstrates during this sequence supports the idea that oral and written language are not primarily learned in a communicative way in autism. This mode of self-taught learning, cracking the code of complex structured information to which they are exposed, goes beyond language learning and finds its extreme expression in autistic "savant" abilities, as we will now see.

\subsection{Special skills and language follow similar development paths in autism.}

There are deep similarities between the way autistic people develop a special ability and their sequence of language acquisition (see Table 1). Most intense interests and autistic special abilities contain a language element [100]. In autism, both language and autistic special abilities are self-taught. Language can develop without the evidence of social reinforcement [15]). Such learning is mainly implicit and favours large scale isomorphic units, as shown by the delayed echolalia of sentences presented in a fixed format. Both involve language in the visual modality (letter recognition) earlier or at a higher level than in typical children, but they are associated with a language delay in a large fraction of the autistic population. Finally, numerous savants present both hyperlexic and another savant ability $[38,101]$.

We propose that exposure to structured material, including language but not limited to it, "triggers" both the development of special abilities and language in autism. However, such language needs to be presented in a more isomorphic manner and with a higher level of structural recurrence (written language, calendars, YouTube nursery rhymes, etc.) than the oral language of their social environment, which is of much more importance for typical children. More importantly, the detection-coupling-syntax developmental scheme may be the same for language and special abilities. Both cases include the following steps: a) detection of structural laws in the chosen material comprised of identical units constituting larger structures, b) mapping of units from one modality to their counterpart in another modality, c) stabilization of the coupling between the homologous elements, and d) generative mastery of a code with several embedded levels, allowing the production of new well-formed utterances.

In short, the heterogeneity of the fields to which scholarly capacities are applied in autism, as well as their structural similarity, allows abstracting the principles at stake beyond the domain of the information involved. Language learning and special abilities in autism may arise from the same mechanism and competence, provided that the class of objects to which they apply is widened. However, this difference does not alter the fundamental principles, which are embedded in human genetic code, thus ruling them. These principles are also, as we shall see, those that govern language learning in typical children.

\subsection{The comparative approach between autistic language and Chomskyan nativism.}

Although their nature is still a subject of debate, there are genetic constraints to the orientation towards oral language and its acquisition. These include the 'innate biases and strategies that place constraints on perception and learning' which 'set the parameters for a particular pattern from among those innately provided' [102]. In Chomskyan nativism [103], the faculty of language - narrow sense (FLN) includes the core computational mechanisms of recursion that allow syntax generativity and its mapping to perceptual and motor interfaces. The acquisition of language is dependent on an ability to recognize language, detect a recursive structure in it, and adapt to one's mother tongue. The high level of abstraction of syntactic universals is revealed in a comparative approach, allowing common and different aspects to emerge between the acquisition of various syntactic structures by humans.

Just as the comparison of human languages defines the level of abstraction of the universals of acquisition and structure specific to human language, comparison of various 
special autistic abilities provides information about their development and common neurocognitive mechanisms. We support Kissine's [15] statement that autism can help us determine the constraints of the level of abstraction needed for the extraction of language structure and language acquisition in humans. This requires, in addition to a simple comparative approach between different realizations of the same ability, a meta-comparison between the plurality of typical language achievements and the plurality of special autistic abilities, which may rely on the same core aptitudes or mechanisms. The meta comparison between autistic and non-autistic deployment of special abilities and language potentiality, respectively, reveal how both manifest a common, human property of language generativity and the mastery of recursive structures. We are therefore at odds with the conclusions of Pinker [104] (p. 62) who wrote 'Together with robots and chimpanzees, people with autism remind us that cultural learning is possible only because neurologically normal people have innate equipment to accomplish it', or Tomasello [105] (p. 689) who wrote 'neither apes nor children with autism have - at least not to the same extent as typically developing human children - the motivation or capacity to share things psychologically with others. This means that they both have very limited skills for creating things culturally with other persons'. For them, the triangular comparison of typical humans - apes - autism results in the rejection of autism outside of species-specific identity.

The emergence of autistic special abilities follows exposure to structured material that shares commonalities with language. The formal properties and our improved understanding of the materials on which autistic intense interests are directed and which permit the development of special abilities reveal common mechanisms and constraints with language. For example, each of the two components of multimodal units, such as perfect pitch, synesthesia, letter denomination, or calendar calculation, all belong to a) finite families of b) highly similar shapes each time they occur, c) presented spatially or sequentially in real terms, and d) structured by complex but recurring constraints (or within/between code isomorphisms). Such invariance suggests that all of these characteristics, albeit quite minimal, are sufficient to trigger an interest or orientation and be the subject of subsequent mastery, including language generativity. The veridical mapping framework implies that the abilities required for language acquisition, such as the mastery of recursive structures, are initially used and developed in other spheres. These are related to autistic children's interests and will subsequently be useful or reused for linguistic decoding. Language progression would then be delayed, and language decoding would therefore be less dependent on social cues and rely more on the structure of the exposed material [71]. It should therefore not be surprising that the acquisition of language is atypical in its timeline, peculiarities, and rigidities.

\section{Material and species specificity.}

\subsection{Cortical reallocation and idiosyncrasy in autism in language-related tasks.}

Language in autism can be understood from the viewpoint of the heterogeneity of autistic language phenotypes - from impaired to exceptional - and the steps of its development [28]. Brain activity associated with oral language is at first abnormally low, and then atypically localised. Children with a genetic predisposition to autism display a hyper-connected auditory-motor association cortex at nine months, but low specialisation for voice [106]. Importantly, around the age of language acquisition, autistic people show enhanced auditory-visual connectivity within the language regions and between them and the visual cortex, consistent with the audio-visual advances observed in multimodal coupling [107]. These alterations, together with a reduction in the lateralisation of activation when exposed to oral speech, are among those that predict an autism diagnosis at 24 months [108]. This pattern can still be observed in adulthood [109,110]. This differentiates between autistic adults with and without an initial speech onset delay, who present with considerable differences in cortical allocation [111,112]. The variability of cerebral allocation in areas of perceptual expertise can therefore be observed both at the individual and group level. When exposed to speech-like material, autistic adults who had a SOD show 
overactivation of the Heschl gyrus and the area responsible for the perceptual part of language processing [112]. Alternatively, autistic adults who did not have a language delay show activation of a large area that includes the brain cortex. This area is activated in neurotypicals when processing language linguistically, and even extends to motor cortices [112].

In the visual modality, there is also greater variability in brain expertise regions. The relative weighting of the activation $[113,114]$ and connectivity $[115,116]$ of perceptual vs. language networks in linguistic tasks deviates towards domain-specific visual expertise. This has been verified in language tasks [117], as well as reasoning tasks [26], in which such hyper-activation is associated with faster performance than typical individuals of the same intelligence [26]. On the other hand, the localization of activation observed during information processing that leads to circumscribed localization in typical people is both different from that of typical people when averaged, and more different between autistic individuals than between typical people [118]. Overall, this suggests widening of the genetic constraints of neural and functional allocation of expertise regions, particularly those devoted to language processing.

\subsection{Autism involves the widening of a genetic constraint toward language material-specificity.}

The variations of brain activity observed between autistic and non-autistic people during linguistic tasks predominate in regions that developed the latest in evolution $[119,120]$ and that maintain cross-modal plasticity during early deprivation of perceptual input [29]. On the other hand, the widening of the material-specific constraints observed in autism during oral language acquisition suggests an alteration of the mechanism responsible for the orientation toward, and selection of, the material producing the first linguistic units in neurotypicals. Therefore, we understand development related to language (and complex information in general) in autistic people as the enlargement of the typical language-specific coupling between brain specialisation and language.

We propose that inborn linguistic parsing mechanisms preferentially orient autistic people toward any material with "embedded structures" - what we have called a high density of isomorphisms - instead of primarily oral communicative language, as in typical people. This extension would apply to any material possessing these properties, possibly to the detriment of oral language. This model is suggested by a) the atypical attention parameters and behaviors that precede the developmental break or language regression and plateau, b) the abstract similitude of the autistic and non-autistic sequence of integration of embedded structures, and c) the enhanced variability of functional and anatomical allocation of the regions involved in the development and use of language in autistic people.

Variability in dominant material-specific constraints or atypical coupling between a specific material and a brain function is the rule and not the exception in phylogenesis, as in individual development. They are found at the individual level following the absence of auditory or visual input (e.g. cross-modal plasticity in early visual impairment [121]) and at the population scale in the recycling of the Visual Word Form Area [122]) at the evolutionary level. They have been conceptualized, with certain differences, as neural reuse [123] or exaptation [124] and were involved in the evolution of human language. Their latest manifestation is the existence of a neural allocation for written code. When the coupling between information processing units and information present in the living environment opens up, as in reading, this is "cultural reuse" [125].

The material specificity for an area of intense interest and the subsequent savant ability are determined by exposure to certain materials and follow prolonged inspection/analysis. Just as there is a critical period for learning the mother tongue for a typical child in the early preschool years, the dedication of a period focused on non-social structured material, within a certain modality, will partially "freeze" the autistic domain of interest. Sa- 
vant abilities may, however, expand toward other domains of structured material, although such expansion is constrained by an isomorphic relationship between domains, such as for special computational abilities or between calendar and tonal structure [101].

\subsection{Does autistic language development fall outside of species-specific characteristics?}

We separate the human specificity in dealing with complex structures - the potential material-specificity for language - from the relative domain-specificity of these mechanisms once they have become established for a particular individual speaking a particular language. We distinguish the material-specificity (the linguistic nature or not of what triggers the processes, of which typical language learning would be a special case) from the domain-specificity inherent to the processing of complex information once such learning has taken place. The specialization of a language for a neurotypical group and specialization of an interest for an autistic person, in particular, would therefore be phenomena of the same nature, resulting from the same, species-specific genetic constraints (Anderson and Penner-Wilger [126]).

The enlargement of the scope of information preferentially processed during infancy in autism does not imply a non-human or super-human autistic nature. Privileging written language, calendars, or visual structures suggests an orientation towards materials that maximize the density of isomorphisms, such as those found in human language. Moreover, most autistic people usually end up speaking and a certain number of them speak earlier and better that the typical population. Beyond the strong similarity between typical language acquisition and autistic special abilities, the level and nature of autistic intelligence confirms that autism belongs to what is most human in humans. A quarter of the siblings of autistic children, who therefore share the same predisposition to autism as their autistic relative, are two standard deviations ahead of the Mullen norms of the nonautistic population at the same age. Forty percent of them have a higher level of nonverbal intelligence than the general population [58]. A previous study showed that when a group of autistic adults were matched to typical adults for global IQ, the autistic group showed much higher intelligence measured by nonverbal reasoning than by a verbal intelligence measure [94]. The common low-effect genetic variants associated with prototypical autism are also those associated with intelligence in typical people $[127,128]$. The level of "severity", as well as the verbal or nonverbal status of an autistic person, is independent of this genetic predisposition to autism $[129,130]$. Prototypical autism is, thus, another combination of verbal and nonverbal intelligence and not an intellectual disability.

Access to language in autism, with its divergences and convergences with predominant paths, results from a deep identity with the access to language that constitutes humanity. Autism consists of the opening of the potentialities of detection, learning, and manipulation of complex human information to families of non-socially determined forms and structures. It has been known since K. Lorenz that the relative absence of fixed material-specific instinctual sequences goes hand in hand with intelligence: crows are smarter than cranes. The extension of the material processed by a genetically transmitted function and its cultural stabilization is undoubtedly a source of human progress - as long as, in the case of autistic people, such diversity is welcome. Neural reuse (or recycling/exaptation) is the norm and not the exception in evolution [124,126]. These apparent inflections in adaptation are involved in what makes humans what they are, specifically in terms of the invention and use of language, and within language, the ability to read. Emphasizing the reduced dependence of autistic people on social triggers in language development, Pinker and Tomasello's major argument in favor of their position toward autism, considers the most species-specific trait in humans to be their least species-specific trait: their gregariousness.

It is necessary to alter the conception of autism as a genetic "error" in favor of an abstraction of the species-specific constraints and abilities to integrate, and potentially master, the complex information they are exposed to. Such accomplishments occur by an original path, which may explain both the success and challenges of autism. The decisions 
taken by the non-autistic majority of humans through scientific models of autistic differences (variants in prototypical autism vs. deleterious mutation in syndromic autism), the anthropological status of these differences (contributory to humanity or a disease to be cured), the delineation between autism and non-autism (categorical or dimensional), and their ethical and societal consequences (to cure or to integrate) are intricate and influence each other. The medical model of autism, that of a genetic "error" to be cured, grounded on a partial interpretation of its genetic component, appears to be a recurrent temptation. It is sometimes based on stretched analogies, such as using mouse-based behaviorist intervention programs as a model for autistic learning. Alternatively, it may also find its rationale in the most sophisticated phylogenetic considerations, such as fine-grained studies of what differentiates humans from apes in reasoning and communication. In both cases, we see the medical model of autism as ethically outdated, scientifically shortsighted, and heuristically sterile.

\subsection{Recognizing the human genetic nature of autistic language learning changes our strategy for intervention.}

The notion of non-communicative language learning does not imply fostering mere passive exposure to information of this nature without interaction with peers. The aim is to make this information accessible [131] to the child and display it in front of him, for example, by using "lateral tutorship", minimizing typical socio-communicative interaction patterns [89]. We thus take the model of exposure to a mother tongue for the typical child, but modify the oral and interactive aspects $[69,71,72]$. The autistic child is minimally interested in a direct guardianship interaction but is an attentive observer and deferred imitator of what he observes. It is thus advisable to make such information work in front of him while integrating it, but without asking his active participation, as manifested by the same behavioral marker criteria as a typical child. By re-attributing the genetically innate capacity to manipulate and extract complex integrated structures to autism, rather than identifying it with a deficit to be treated and to use social cues, we will discover a new rationale to guide our intervention strategies. Access to literacy phone/tablet applications, which children learn to use on their own or because they have seen them work in front of them, is thus a promising avenue. The entry into oral language via the written code, through the manipulation (without specific instructions) of online applications by the child, therefore represents a research theme to prioritize.

Author Contributions: Conceptualization, L.M.; Writing - Original Draft Preparation, L.M., A.O., and D.G.; Writing - Review \& Editing, L.M., A.O., and D.G.; Supervision, L.M.; Funding Acquisition, L.M.

Funding: This research was funded by Marcel \& Rolande Gosselin Research Chair in autism at the University of Montreal.

Acknowledgments: The authors would like to thank Dr Mikhail Kissine for his comments on a previous version of this manuscript.

Conflicts of Interest: The authors declare no conflict of interest. The sponsors had no role in the design, execution, interpretation, or writing of the study.

\section{References}

1. American Psychiatric Association. Diagnostic and statistical manual of mental disorders (DSM- $\left.{ }^{\circledR}\right)$ Fifth Edition; American Psychiatric Publishing: Arlington, VA, 2013; p. 991.

2. Elsabbagh, M.; Divan, G.; Koh, Y.J.; Kim, Y.S.; Kauchali, S.; Marcín, C.; Montiel-Nava, C.; Patel, V.; Paula, C.S.; Wang, C.; et al. Global prevalence of autism and other pervasive developmental disorders. Autism Res 2012, 5, 160-179, doi:10.1002/aur.239. 
3. Charman, T.; Drew, A.; Baird, C.; Baird, G. Measuring early language development in preschool children with autism spectrum disorder using the MacArthur Communicative Development Inventory (Infant Form). J Child Lang 2003, 30, 213-236.

4. Luyster, R.; Lopez, K.; Lord, C. Characterizing communicative development in children referred for autism spectrum disorders using the MacArthur-Bates Communicative Development Inventory (CDI). J Child Lang 2007, 34, 623-654, doi:10.1017/s0305000907008094.

5. Mottron, L.; Dawson, M.; Soulieres, I. Enhanced perception in savant syndrome: patterns, structure and creativity. Philos Trans R Soc Lond B Biol Sci 2009, 364, 1385-1391, doi:364/1522/1385 [pii] 10.1098/rstb.2008.0333.

6. Constantino, J.N. New guidance to seekers of autism biomarkers: an update from studies of identical twins. Mol Autism 2021, 12, 28, doi:10.1186/s13229-021-00434-w.

7. Tammimies, K.; Marshall, C.R.; Walker, S.; Kaur, G.; Thiruvahindrapuram, B.; Lionel, A.C.; Yuen, R.K.; Uddin, M.; Roberts, W.; Weksberg, R.; et al. Molecular Diagnostic Yield of Chromosomal Microarray Analysis and Whole-Exome Sequencing in Children With Autism Spectrum Disorder. JAMA 2015, 314, 895-903, doi:10.1001/jama.2015.10078.

8. Mottron, L. A radical change in our autism research strategy is needed: Back to prototypes. Autism Res 2021; online ahead of print 2 June 2021, doi:10.1002/aur.2494.

9. Mottron, L. Progress in autism research requires several recognition-definition-investigation cycles. Autism Res 2021; online ahead of print 2 June 2021, doi:10.1002/aur.2524.

10. Kuhl, P.K. Early language acquisition: cracking the speech code. Nat Rev Neurosci 2004, 5, 831-843, doi:10.1038/nrn1533.

11. Toma, C.; Hervas, A.; Torrico, B.; Balmana, N.; Salgado, M.; Maristany, M.; Vilella, E.; Martinez-Leal, R.; Planelles, M.I.; Cusco, I.; et al. Analysis of two language-related genes in autism: a case-control association study of FOXP2 and CNTNAP2. Psychiatr Genet 2013, 23, 82-85, doi:10.1097/YPG.0b013e32835d6fc6.

12. Lombardo, M.V.; Courchesne, E.; Lewis, N.E.; Pramparo, T. Hierarchical cortical transcriptome disorganization in autism. Mol Autism 2017, 8, 29, doi:10.1186/s13229-017-0147-7.

13. Lombardo, M.V.; Lai, M.C.; Baron-Cohen, S. Big data approaches to decomposing heterogeneity across the autism spectrum. Mol Psychiatry 2019, 24, 1435-1450, doi:10.1038/s41380-018-0321-0.

14. Schovanec, J.; Amelsen, J.; Revil, S. Je suis à l'est ! : savant et autiste : un témoignage unique; Plon, Ed.; Paris, 2012; p. 246.

15. Kissine, M. Perspectives: Autism, constructionism and nativism. Language 2020.

16. Burack, J.A.; larocci, G.; Bowler, D.; Mottron, L. Benefits and pitfalls in the merging of disciplines: the example of developmental psychopathology and the study of persons with autism. Dev Psychopathol 2002, 14, 225-237.

17. Mottron, L.; Dawson, M.; Soulières, I.; Dawson, M. A different memory: are distinctions drawn from the study of nonautistic memory appropriate to describe memory in autism? In Memory in Autism, Boucher, J., Bowler, D., Eds.; Cambridge University Press: 2008; pp. 311-329.

18. Midgley, J.M.; MacLachlan, J.; Watson, D.G. An extraction-derivatization method suitable for the analysis of biogenic amines by gas chromatography negative ion mass spectrometry. Biomed Environ Mass Spectrom 1988, 15, 535-539, doi:10.1002/bms.1200151005.

19. Meilleur, A.A.; Jelenic, P.; Mottron, L. Prevalence of Clinically and Empirically Defined Talents and Strengths in Autism. J Autism Dev Disord 2014, doi:10.1007/s10803-014-2296-2. 
20. Mayer, J.L.; Hannent, I.; Heaton, P.F. Mapping the Developmental Trajectory and Correlates of Enhanced Pitch Perception on Speech Processing in Adults with ASD. J Autism Dev Disord 2016, 46, 1562-1573, doi:10.1007/s10803-014-2207-6.

21. Stanutz, S.; Wapnick, J.; Burack, J.A. Pitch discrimination and melodic memory in children with autism spectrum disorders. Autism 2014, 18, 137-147, doi:10.1177/1362361312462905.

22. Barbeau, E.; Soulieres, I.; Dawson, M.; Zeffiro, T.A.; Mottron, L. The level and nature of autistic intelligence III: Inspection time. J Abnorm Psychol 2013, 122, 295-301.

23. Kaldy, Z.; Kraper, C.; Carter, A.S.; Blaser, E. Toddlers with Autism Spectrum Disorder are more successful at visual search than typically developing toddlers. Dev Sci 2011, 14, 980-988, doi:10.1111/j.14677687.2011.01053.x.

24. Weiss, M.W.; Sharda, M.; Lense, M.; Hyde, K.L.; Trehub, S.E. Enhanced Memory for Vocal Melodies in Autism Spectrum Disorder and Williams Syndrome. Autism Res 2021, 14, 1127-1133, doi:10.1002/aur.2462.

25. Soulieres, I.; Zeffiro, T.A.; Girard, M.L.; Mottron, L. Enhanced mental image mapping in autism. Neuropsychologia 2011, 49, 848-857, doi:S0028-3932(11)00032-7 [pii]

10.1016/j.neuropsychologia.2011.01.027.

26. Soulieres, I.; Dawson, M.; Samson, F.; Barbeau, E.B.; Sahyoun, C.P.; Strangman, G.E.; Zeffiro, T.A.; Mottron, L. Enhanced visual processing contributes to matrix reasoning in autism. Hum Brain Mapp 2009, 30, 40824107.

27. Mottron, L.; Dawson, M.; Soulieres, I.; Hubert, B.; Burack, J. Enhanced perceptual functioning in autism: an update, and eight principles of autistic perception. J Autism Dev Disord 2006, 36, 27-43, doi:10.1007/s10803005-0040-7.

28. Mottron, L.; Bouvet, L.; Bonnel, A.; Samson, F.; Burack, J.A.; Dawson, M.; Heaton, P. Veridical mapping in the development of exceptional autistic abilities. Neurosci Biobehav Rev 2013, 37, 209-228, doi:10.1016/j.neubiorev.2012.11.016.

29. Mottron, L.; Belleville, S.; Rouleau, G.A.; Collignon, O. Linking neocortical, cognitive, and genetic variability in autism with alterations of brain plasticity: The Trigger-Threshold-Target model. Neurosci Biobehav Rev 2014, 47C, 735-752, doi:10.1016/j.neubiorev.2014.07.012.

30. Pring, L.; Hermelin, B. Numbers and letters: exploring an autistic savant's unpracticed ability. Neurocase 2002, 8, 330-337, doi:10.1076/neur.8.3.330.16193.

31. Heaton, P.; Williams, K.; Cummins, O.; Happe, F. Autism and pitch processing splinter skills: a group and subgroup analysis. Autism 2008, 12, 203-219, doi:12/2/203 [pii] 10.1177/1362361307085270.

32. Neufeld, J.; Roy, M.; Zapf, A.; Sinke, C.; Emrich, H.M.; Prox-Vagedes, V.; Dillo, W.; Zedler, M. Is synesthesia more common in patients with Asperger syndrome? Front Hum Neurosci 2013, 7, 847, doi:10.3389/fnhum.2013.00847.

33. Baron-Cohen, S.; Johnson, D.; Asher, J.; Wheelwright, S.; Fisher, S.E.; Gregersen, P.K.; Allison, C. Is synaesthesia more common in autism? Mol Autism 2013, 4, 40, doi:10.1186/2040-2392-4-40.

34. Solazzo, S.; Kojovic, N.; Robain, F.; Schaer, M. Measuring the Emergence of Specific Abilities in Young Children with Autism Spectrum Disorders: The Example of Early Hyperlexic Traits. Brain Sci 2021, 11, doi:10.3390/brainsci11060692.

35. Ostrolenk, A.; d'Arc, B.F.; Jelenic, P.; Samson, F.; Mottron, L. Hyperlexia: Systematic review, neurocognitive modelling, and outcome. Neuroscience and Biobehavioral Reviews 2017, 79, 134-149, doi:10.1016/j.neubiorev.2017.04.029.

36. Miller, L.K. The savant syndrome: intellectual impairment and exceptional skill. Psychol Bull 1999, 125, 31-46. 
37. Heaton, P.; Wallace, G.L. Annotation: the savant syndrome. J Child Psychol Psychiatry 2004, 45, 899-911, doi:10.1111/j.1469-7610.2004.t01-1-00284.x JCPP284 [pii].

38. Mottron, L.; Lemmens, K.; Gagnon, L.; Seron, X. Non-algorithmic access to calendar information in a calendar calculator with autism. J Autism Dev Disord 2006, 36, 239-247, doi:10.1007/s10803-005-0059-9.

39. American Psychiatric Association. Diagnostic and statistical manual of mental disorders : DSM-III-R, 3rd ed.; American Psychiatric Association: Washington, DC, 1987; pp. xxix, 567 p.

40. Constantino, J.N. Response to "A Radical Change in Our Autism Research Strategy is Needed: Back to Prototypes" by Mottron et al. (2021). Autism Res 2021; online ahead of print 2 June 2021, doi:10.1002/aur.2529.

41. Bouchard, T.J. The Wilson Effect: the increase in heritability of IQ with age. Twin Res Hum Genet 2013, 16, 923-930, doi:10.1017/thg.2013.54.

42. Mattila, M.L.; Kielinen, M.; Jussila, K.; Linna, S.L.; Bloigu, R.; Ebeling, H.; Moilanen, I. An epidemiological and diagnostic study of Asperger syndrome according to four sets of diagnostic criteria. J Am Acad Child Adolesc Psychiatry 2007, 46, 636-646, doi:10.1097/chi.0b013e318033ff42.

43. Leyfer, O.T.; Tager-Flusberg, H.; Dowd, M.; Tomblin, J.B.; Folstein, S.E. Overlap between autism and specific language impairment: comparison of Autism Diagnostic Interview and Autism Diagnostic Observation Schedule scores. Autism Res 2008, 1, 284-296, doi:10.1002/aur.43.

44. Chawarska, K.; Paul, R.; Klin, A.; Hannigen, S.; Dichtel, L.E.; Volkmar, F. Parental recognition of developmental problems in toddlers with autism spectrum disorders. J Autism Dev Disord 2007, 37, 62-72, doi:10.1007/s10803-006-0330-8.

45. De Giacomo, A.; Fombonne, E. Parental recognition of developmental abnormalities in autism. Eur Child Adolesc Psychiatry 1998, 7, 131-136.

46. Sacrey, L.A.; Zwaigenbaum, L.; Bryson, S.; Brian, J.; Smith, I.M.; Roberts, W.; Szatmari, P.; Roncadin, C.; Garon, N.; Novak, C.; et al. Can parents' concerns predict autism spectrum disorder? A prospective study of high-risk siblings from 6 to 36 months of age. J Am Acad Child Adolesc Psychiatry 2015, 54, 470-478, doi:10.1016/j.jaac.2015.03.014.

47. Zwaigenbaum, L.; Bryson, S.; Garon, N. Early identification of autism spectrum disorders. Behav Brain Res 2013, 251, 133-146, doi:10.1016/j.bbr.2013.04.004.

48. Bedford, R.; Pickles, A.; Gliga, T.; Elsabbagh, M.; Charman, T.; Johnson, M.H.; Team, B. Additive effects of social and non-social attention during infancy relate to later autism spectrum disorder. Dev Sci 2014, 17, 612-620, doi:10.1111/desc.12139.

49. Wolff, J.J.; Dimian, A.F.; Botteron, K.N.; Dager, S.R.; Elison, J.T.; Estes, A.M.; Hazlett, H.C.; Schultz, R.T.; Zwaigenbaum, L.; Piven, J.; et al. A longitudinal study of parent-reported sensory responsiveness in toddlers at-risk for autism. J Child Psychol Psychiatry 2019, 60, 314-324, doi:10.1111/jcpp.12978.

50. Canu, D.; Van der Paelt, S.; Canal-Bedia, R.; Posada, M.; Vanvuchelen, M.; Roeyers, H. Early non-social behavioural indicators of autism spectrum disorder (ASD) in siblings at elevated likelihood for ASD: a systematic review. Eur Child Adolesc Psychiatry 2020, doi:10.1007/s00787-020-01487-7.

51. Zwaigenbaum, L.; Bryson, S.; Rogers, T.; Roberts, W.; Brian, J.; Szatmari, P. Behavioral manifestations of autism in the first year of life. Int J Dev Neurosci 2005, 23, 143-152, doi:S0736574804000553 [pii] 10.1016/j.ijdevneu.2004.05.001.

52. Elsabbagh, M.; Fernandes, J.; Webb, S.J.; Dawson, G.; Charman, T.; Johnson, M.H.; British Autism Study of Infant Siblings, T. Disengagement of visual attention in infancy is associated with emerging autism in toddlerhood. Biol Psychiatry 2013, 74, 189-194, doi:10.1016/j.biopsych.2012.11.030. 
53. Ozonoff, S.; Macari, S.; Young, G.S.; Goldring, S.; Thompson, M.; Rogers, S.J. Atypical object exploration at 12 months of age is associated with autism in a prospective sample. Autism 2008, 12, 457-472, doi:10.1177/1362361308096402.

54. Elsabbagh, M.; Volein, A.; Holmboe, K.; Tucker, L.; Csibra, G.; Baron-Cohen, S.; Bolton, P.; Charman, T.; Baird, G.; Johnson, M.H. Visual orienting in the early broader autism phenotype: disengagement and facilitation. $J$ Child Psychol Psychiatry 2009, 50, 637-642, doi:10.1111/j.1469-7610.2008.02051.x.

55. Cheung, C.H.M.; Bedford, R.; Johnson, M.H.; Charman, T.; Gliga, T.; team, B. Visual search performance in infants associates with later ASD diagnosis. Dev Cogn Neurosci 2018, 29, 4-10, doi:10.1016/j.den.2016.09.003.

56. Gliga, T.; Bedford, R.; Charman, T.; Johnson, M.H.; Team, B. Enhanced Visual Search in Infancy Predicts Emerging Autism Symptoms. Curr Biol 2015, 25, 1727-1730, doi:10.1016/j.cub.2015.05.011.

57. Kaldy, Z.; Giserman, I.; Carter, A.S.; Blaser, E. The Mechanisms Underlying the ASD Advantage in Visual Search. J Autism Dev Disord 2016, 46, 1513-1527, doi:10.1007/s10803-013-1957-x.

58. Landa, R.J.; Gross, A.L.; Stuart, E.A.; Bauman, M. Latent class analysis of early developmental trajectory in baby siblings of children with autism. J Child Psychol Psychiatry 2012, 53, 986-996, doi:10.1111/j.14697610.2012.02558.x.

59. Schwartz, S.; Wang, L.; Shinn-Cunningham, B.G.; Tager-Flusberg, H. Atypical Perception of Sounds in Minimally and Low Verbal Children and Adolescents With Autism as Revealed by Behavioral and Neural Measures. Autism Res 2020, 13, 1718-1729, doi:10.1002/aur.2363.

60. Bussu, G.; Jones, E.J.H.; Charman, T.; Johnson, M.H.; Buitelaar, J.K.; Team, B. Latent trajectories of adaptive behaviour in infants at high and low familial risk for autism spectrum disorder. Mol Autism 2019, 10, 13, doi:10.1186/s13229-019-0264-6.

61. Landa, R.J.; Gross, A.L.; Stuart, E.A.; Faherty, A. Developmental trajectories in children with and without autism spectrum disorders: the first 3 years. Child Dev 2013, 84, 429-442, doi:10.1111/j.14678624.2012.01870.x.

62. Bruyneel, E.; Demurie, E.; Warreyn, P.; Beyers, W.; Boterberg, S.; Bontinck, C.; Dewaele, N.; Roeyers, H. Language growth in very young siblings at risk for autism spectrum disorder. Int J Lang Commun Disord 2019, 54, 940-953, doi:10.1111/1460-6984.12497.

63. Gagnon, D.; Zeribi, A.; Douard, E.; Courchesne, V.; Rodriguez-Herreros, B.; Huguet, G.; Jacquemont, S.; Loum, M.A.; Mottron, L. Bayonet-shaped language development in autism with regression: a retrospective study. Mol Autism 2021, 12, 35, doi:10.1186/s13229-021-00444-8.

64. Perkins, M.R.; Dobbinson, S.; Boucher, J.; Bol, S.; Bloom, P. Lexical knowledge and lexical use in autism. J Autism Dev Disord 2006, 36, 795-805, doi:10.1007/s10803-006-0120-3.

65. Huttenlocher, P.R.; Huttenlocher, J. A study of children with hyperlexia. Neurology 1973, 23, 1107-1116, doi:https://doi.org/10.1212/WNL.23.10.1107.

66. Craig, H.K.; Telfer, A.S. Hyperlexia and Autism Spectrum Disorder: A Case Study of Scaffolding Language Growth over Time. Top. Lang. Disord. 2005, 25, 11, doi:http://dx.doi.org/10.1097/00011363-20051000000011.

67. Atkin, K.; Lorch, M.P. Hyperlexia in a 4-year-old boy with Autistic Spectrum Disorder. J Neurolinguist 2006, 19, 253-269, doi:10.1016/J.jneuroling.2005.11.006.

68. Kasari, C.; Brady, N.; Lord, C.; Tager-Flusberg, H. Assessing the minimally verbal school-aged child with autism spectrum disorder. Autism Res 2013, 6, 479-493, doi:10.1002/aur.1334. 
69. Ostrolenk, A.; Forgeot d'Arc, B.; Jelenic, P.; Samson, F.; Mottron, L. Hyperlexia: Systematic review, neurocognitive modelling, and outcome. Neurosci Biobehav Rev 2017, 79, 134-149, doi:10.1016/j.neubiorev.2017.04.029.

70. U.S. Department of Education. Typical Language Accomplishments for Children, Birth to Age 6 -- Helping Your Child Become a Reader; https://www2.ed.gov/parents/academic/help/reader/part9.html. 2003.

71. Kissine, M.; Luffin, X.; Aiad, F.; Bourourou, M.; Deliens, G.; Gaddour, N. Noncolloquial Arabic in Tunisian Children With Autism Spectrum Disorder: A Possible Instance of Language Acquisition in a Noninteractive Context. Language Learning 2018, 69, doi:https://doi.org/10.1111/lang.12312.

72. Mottron, L. Should we change targets and methods of early intervention in autism, in favor of a strengthsbased education? Eur Child Adolesc Psychiatry 2017, doi:10.1007/s00787-017-0955-5.

73. Fay, W.H.; Butler, B.V. Echolalia, IQ, and the developmental dichotomy of speech and language systems. J Speech Hear Res 1968, 11, 365-371, doi:10.1044/jshr.1102.365.

74. Fay, W.H. Personal pronouns and the autistic child. J Autism Dev Disord 1979, 9, 247-260.

75. Paccia, J.M.; Curcio, F. Language processing and forms of immediate echolalia in autistic children. J Speech Hear Res 1982, 25, 42-47, doi:10.1044/jshr.2501.42.

76. Fay, W.H. Mitigated echolalia of children. J Speech Hear Res 1967, 10, 305-310, doi:10.1044/jshr.1002.305.

77. Roberts, J.M. Echolalia and comprehension in autistic children. J Autism Dev Disord 1989, 19, 271-281, doi:10.1007/BF02211846.

78. Prizant, B.M. Language acquisition and communicative behavior in autism: toward an understanding of the "whole" of it. J Speech Hear Disord 1983, 48, 296-307.

79. Prizant, B.M.; Duchan, J.F. The functions of immediate echolalia in autistic children. J Speech Hear Disord 1981, 46, 241-249.

80. Lord, C.; Rutter, M.; Le Couteur, A. Autism Diagnostic Interview-Revised: a revised version of a diagnostic interview for caregivers of individuals with possible pervasive developmental disorders. J Autism Dev Disord 1994, 24, 659-685.

81. Howlin, P. Can Early Interventions Alter the Course of Autism? Novartis Found Symp 2003, 251, 250-259; discussion 260-265, 281-297.

82. Wodka, E.L.; Mathy, P.; Kalb, L. Predictors of phrase and fluent speech in children with autism and severe language delay. Pediatrics 2013, 131, e1128-1134, doi:10.1542/peds.2012-2221.

83. Pickles, A.; Anderson, D.K.; Lord, C. Heterogeneity and plasticity in the development of language: a 17-year follow-up of children referred early for possible autism. J Child Psychol Psychiatry 2014, 55, 1354-1362, doi:10.1111/jcpp.12269.

84. Rutter, M.; Lockyer, L. A five to fifteen year follow-up study of infantile psychosis. I. Description of sample. Br J Psychiatry 1967, 113, 1169-1182.

85. Pickett, E.; Pullara, O.; O'Grady, J.; Gordon, B. Speech acquisition in older nonverbal individuals with autism: a review of features, methods, and prognosis. Cogn Behav Neurol 2009, 22, 1-21, doi:10.1097/WNN.0b013e318190d185.

86. Windsor, J.; Doyle, S.S.; Siegel, G.M. Language acquisition after mutism: a longitudinal case study of autism. J Speech Hear Res 1994, 37, 96-105, doi:10.1044/jshr.3701.96.

87. Fountain, C.; Winter, A.S.; Bearman, P.S. Six Developmental Trajectories Characterize Children With Autism. Pediatrics 2012, 129, E1112-E1120, doi:10.1542/peds.2011-1601.

88. Kanner, L. The conception of wholes and parts in early infantile autism. American Journal of Psychiatry 1951, $108,23-26$. 
89. Cobrinik, L. Unusual reading ability in severely disturbved children. Clinical obserbation and a retrospective inquiry. J Autism Child Schizophr 1974, 4, 163-175, doi:10.1007/BF02105368.

90. O'Connor, N.; Hermelin, B. Two autistic savant readers. J Autism Dev Disord 1994, 24, 501-515, doi:10.1007/BF02172131.

91. Sandbank, M.; Bottema-Beutel, K.; Woynaroski, T. Intervention Recommendations for Children With Autism in Light of a Changing Evidence Base. JAMA Pediatr 2020, doi:10.1001/jamapediatrics.2020.4730.

92. Green, J.; Garg, S. Annual Research Review: The state of autism intervention science: progress, target psychological and biological mechanisms and future prospects. J Child Psychol Psychiatry 2018, 59, 424-443, doi:10.1111/jcpp.12892.

93. Brignell, A.; Chenausky, K.V.; Song, H.; Zhu, J.; Suo, C.; Morgan, A.T. Communication interventions for autism spectrum disorder in minimally verbal children. Cochrane Database Syst Rev 2018, 11, CD012324, doi:10.1002/14651858.CD012324.pub2.

94. Dawson, M.; Soulieres, I.; Gernsbacher, M.A.; Mottron, L. The level and nature of autistic intelligence. Psychol Sci 2007, 18, 657-662, doi:PSCI1954 [pii] 10.1111/j.1467-9280.2007.01954.x.

95. Norrelgen, F.; Fernell, E.; Eriksson, M.; Hedvall, A.; Persson, C.; Sjolin, M.; Gillberg, C.; Kjellmer, L. Children with autism spectrum disorders who do not develop phrase speech in the preschool years. Autism 2015, 19, 934-943, doi:10.1177/1362361314556782.

96. Rose, V.; Trembath, D.; Keen, D.; Paynter, J. The proportion of minimally verbal children with autism spectrum disorder in a community-based early intervention programme. J Intellect Disabil Res 2016, 60, 464477, doi:10.1111/jir.12284.

97. Anderson, D.K.; Lord, C.; Risi, S.; DiLavore, P.S.; Shulman, C.; Thurm, A.; Welch, K.; Pickles, A. Patterns of growth in verbal abilities among children with autism spectrum disorder. J Consult Clin Psychol 2007, 75, 594-604, doi:10.1037/0022-006x.75.4.594.

98. Tager-Flusberg, H.; Kasari, C. Minimally verbal school-aged children with autism spectrum disorder: the neglected end of the spectrum. Autism Res 2013, 6, 468-478, doi:10.1002/aur.1329.

99. Knight, E.; Blacher, J.; Eisenhower, A. Predicting reading comprehension in young children with autism spectrum disorder. Sch Psychol 2019, 34, 168-177, doi:10.1037/spq0000277.

100. Klin, A.; Danovitch, J.H.; Merz, A.B.; Volkmar, F.R. Circumscribed interests in higher functioning individuals with Autism spectrum disorders: An exploratory study. Research \& Practice for Persons with Severe Disabilities 2007, 32, 11.

101. Bouvet, L.; Donnadieu, S.; Valdois, S.; Caron, C.; Dawson, M.; Mottron, L. Veridical mapping in savant abilities, absolute pitch, and synesthesia: an autism case study. Front Psychol 2014, 5, 106, doi:10.3389/fpsyg.2014.00106.

102. Kuhl, P.K. A new view of language acquisition. Proc Natl Acad Sci U S A 2000, 97, 11850-11857.

103. Hauser, M.D.; Chomsky, N.; Fitch, W.T. The faculty of language: what is it, who has it, and how did it evolve? Science 2002, 298, 1569-1579.

104. Pinker, S. The blank slate: The Modern Denial of Human Nature; Viking Penguin: New York, USA, $2002 ;$ p. 509.

105. Tomasello, M.; Carpenter, M.; Call, J.; Behne, T.; Moll, H. Understanding and sharing intentions: the origins of cultural cognition. Behav Brain Sci 2005, 28, 675-691; discussion 691-735, doi:10.1017/S0140525X05000129. 
106. Blasi, A.; Lloyd-Fox, S.; Sethna, V.; Brammer, M.J.; Mercure, E.; Murray, L.; Williams, S.C.; Simmons, A.; Murphy, D.G.; Johnson, M.H. Atypical processing of voice sounds in infants at risk for autism spectrum disorder. Cortex 2015, 71, 122-133, doi:10.1016/j.cortex.2015.06.015.

107. Gao, Y.; Linke, A.; Jao Keehn, R.J.; Punyamurthula, S.; Jahedi, A.; Gates, K.; Fishman, I.; Muller, R.A. The language network in autism: Atypical functional connectivity with default mode and visual regions. Autism Res 2019, 12, 1344-1355, doi:10.1002/aur.2171.

108. Emerson, R.W.; Adams, C.; Nishino, T.; Hazlett, H.C.; Wolff, J.J.; Zwaigenbaum, L.; Constantino, J.N.; Shen, M.D.; Swanson, M.R.; Elison, J.T.; et al. Functional neuroimaging of high-risk 6-month-old infants predicts a diagnosis of autism at 24 months of age. Sci Transl Med 2017, 9, doi:10.1126/scitranslmed.aag2882.

109. Eyler, L.T.; Pierce, K.; Courchesne, E. A failure of left temporal cortex to specialize for language is an early emerging and fundamental property of autism. Brain 2012, 135, 949-960, doi:10.1093/brain/awr364.

110. Anderson, J.S.; Druzgal, T.J.; Froehlich, A.; DuBray, M.B.; Lange, N.; Alexander, A.L.; Abildskov, T.; Nielsen, J.A.; Cariello, A.N.; Cooperrider, J.R.; et al. Decreased interhemispheric functional connectivity in autism. Cereb Cortex 2011, 21, 1134-1146, doi:10.1093/cercor/bhq190.

111. Barbeau, E.B.; Klein, D.; Soulières, I.; Petrides, M.; Bernhardt, B.C.; Mottron, L. Age of Speech Onset in Autism Relates to Structural Connectivity in the Language Network. Cerebral Cortex Communications 2020, 1, doi:https://doi.org/10.1093/texcom/tgaa077.

112. Samson, F.; Zeffiro, T.A.; Doyon, J.; Benali, H.; Mottron, L. Speech acquisition predicts regions of enhanced cortical response to auditory stimulation in autism spectrum individuals. J Psychiatr Res 2015, 68, 285-292, doi:10.1016/j.jpsychires.2015.05.011.

113. Gaffrey, M.S.; Kleinhans, N.M.; Haist, F.; Akshoomoff, N.; Campbell, A.; Courchesne, E.; Muller, R.A. Atypical [corrected] participation of visual cortex during word processing in autism: an fMRI study of semantic decision. Neuropsychologia 2007, 45, 1672-1684, doi:S0028-3932(07)00025-5 [pii] 10.1016/j.neuropsychologia.2007.01.008.

114. Samson, F.; Mottron, L.; Soulieres, I.; Zeffiro, T.A. Enhanced visual functioning in autism: An ALE metaanalysis. 2011, doi:10.1002/hbm.21307.

115. Maximo, J.O.; Kana, R.K. Aberrant "deep connectivity" in autism: A cortico-subcortical functional connectivity magnetic resonance imaging study. Autism Res 2019, 12, 384-400, doi:10.1002/aur.2058.

116. Hong, S.J.; Vos de Wael, R.; Bethlehem, R.A.I.; Lariviere, S.; Paquola, C.; Valk, S.L.; Milham, M.P.; Di Martino, A.; Margulies, D.S.; Smallwood, J.; et al. Atypical functional connectome hierarchy in autism. Nat Commun 2019, 10, 1022, doi:10.1038/s41467-019-08944-1.

117. Kana, R.K.; Keller, T.A.; Cherkassky, V.L.; Minshew, N.J.; Just, M.A. Sentence comprehension in autism: thinking in pictures with decreased functional connectivity. Brain 2006, 129, 2484-2493.

118. Poulin-Lord, M.P.; Barbeau, E.B.; Soulieres, I.; Monchi, O.; Doyon, J.; Benali, H.; Mottron, L. Increased topographical variability of task-related activation in perceptive and motor associative regions in adult autistics. Neuroimage Clin 2014, 4, 444-453.

119. Mottron, L.; Duret, P.; Mueller, S.; Moore, R.D.; Forgeot d'Arc, B.; Jacquemont, S.; Xiong, L. Sex differences in brain plasticity: a new hypothesis for sex ratio bias in autism. Mol Autism 2015, 6, 33, doi:10.1186/s13229015-0024-1.

120. Duret, P.; Samson, F.; Pinsard, B.; Barbeau, E.B.; Boré, A.; Soulières, I.; Mottron, L. Gyrification changes are related to cognitive strengths in autism. Neuroimage Clin 2018, 20, 415-423, doi:10.1016/j.nicl.2018.04.036. 
121. Collignon, O.; Lassonde, M.; Lepore, F.; Bastien, D.; Veraart, C. Functional cerebral reorganization for auditory spatial processing and auditory substitution of vision in early blind subjects. Cereb Cortex 2007, 17, 457-465, doi:10.1093/cercor/bhj162.

122. Dehaene-Lambertz, G.; Monzalvo, K.; Dehaene, S. The emergence of the visual word form: Longitudinal evolution of category-specific ventral visual areas during reading acquisition. PLoS Biol 2018, 16, e2004103, doi:10.1371/journal.pbio.2004103.

123. Anderson, M.L. Neural reuse: a fundamental organizational principle of the brain. Behav Brain Sci 2010, 33, 245-266; discussion 266-313, doi:10.1017/S0140525X10000853.

124. Gould, S.J.; Lloyd, E.A. Individuality and adaptation across levels of selection: how shall we name and generalize the unit of Darwinism? Proc Natl Acad Sci U S A 1999, 96, 11904-11909, doi:10.1073/pnas.96.21.11904.

125. Colagè, I.; D'Ambrosio, P. Exaptation and Neural Reuse: A research prerspective in human specificity. Antonianum 2014, 89, 333-358.

126. Anderson, M.L.; Penner-Wilger, M. Neural reuse in the evolution and development of the brain: evidence for developmental homology? Dev Psychobiol 2013, 55, 42-51, doi:10.1002/dev.21055.

127. Clarke, T.K.; Lupton, M.K.; Fernandez-Pujals, A.M.; Starr, J.; Davies, G.; Cox, S.; Pattie, A.; Liewald, D.C.; Hall, L.S.; MacIntyre, D.J.; et al. Common polygenic risk for autism spectrum disorder (ASD) is associated with cognitive ability in the general population. Mol Psychiatry 2016, 21, 419-425, doi:10.1038/mp.2015.12.

128. Savage, J.E.; Jansen, P.R.; Stringer, S.; Watanabe, K.; Bryois, J.; de Leeuw, C.A.; Nagel, M.; Awasthi, S.; Barr, P.B.; Coleman, J.R.I.; et al. Genome-wide association meta-analysis in 269,867 individuals identifies new genetic and functional links to intelligence. Nat Genet 2018, 50, 912-919, doi:10.1038/s41588-018-0152-6.

129. Pohl, A.; Jones, W.R.; Marrus, N.; Zhang, Y.; Klin, A.; Constantino, J.N. Behavioral predictors of autism recurrence are genetically independent and influence social reciprocity: evidence that polygenic ASD risk is mediated by separable elements of developmental liability. Transl Psychiatry 2019, 9, 202, doi:10.1038/s41398-019-0545-z.

130. Castelbaum, L.; Sylvester, C.M.; Zhang, Y.; Yu, Q.; Constantino, J.N. On the Nature of Monozygotic Twin Concordance and Discordance for Autistic Trait Severity: A Quantitative Analysis. Behav Genet 2020, 50, 263272, doi:10.1007/s10519-019-09987-2.

131. Dawson, M.; Mottron, L.; Gernsbacher, M.A. Learning in autism. In Learning and memory: a comprehensive reference. In Cognitive psychology, Roediger, J.B., H, L., Eds.; Elsevier: Oxford, UK, 2008; pp. 759-772. 